\title{
STRATEGI PEMASARANPUBLIC RELATIONS MD ENTERTAINMENT PADA PEMASARAN FILM HABIBIE \& AINUN
}

\author{
Trisna Adi Perman, Lilis Puspitasari \\ Program Studi Hubungan Masyarakat, Fakultas Ilmu Komunikasi, Universitas Padjadjaran
}

\begin{abstract}
ABSTRAK
Tujuan penelitian ini adalah untuk mengetahui perencanaan, implementasi serta evaluasi dari strategi Marketing Public Relations yang ditetapkan PR MD Entertainment pada film Habibie \& Ainun pada tahun 2012-2013. Metode yang dilakukan adalah metode deskriptif yang bertujuan melukiskan secara sistematis fakta atau karakteristik populasi tertentu atau bidang tertentu secara faktual dan cermat. Hasil penelitian menunjukan PR MD Entertainment telah melakukan tahapan-tahapan atau Teknik PR pada film Habiebie dan Ainun dengan melakukan perencanaan, implementasi serta evaluasi dari program tersebut dari tahun 20122013. Kesimpulan penelitian ini adalah PR MD Entertainment melakukan perencanaan Strategi Marketing PR Film Habibie \& Ainun, telah dilakukan dengan baik dan melalui proses persiapkan yang sangat matang, tahap implementasi strategi MPR MD Entertainment pada pemasaran Film Habibie \& Ainun meliputi apa, siapa dan bagaimana proses penyampaian pesan-pesan yang akan disampaikan kepada masyarakat. Penggunaan berbagai taktik MPR baik dalam bentuk Offline, Online dan Ground Activity yang menekankan pada Unique Selling point dari tokoh yang diangkat, disertai advertising/iklan, publisitas, merchandising dan dibantu oleh kekuatan word of mouth yang dilakukan oleh media serta Evaluasi Strategi juga dilakukan oleh PR MD Entertainment, diawali dengan melakukan Media Monitoring, serta mencari apa kekurangan, kelebihan, kendala yang dihadapi timnya dalam melaksanakan tugas.Saran penelitian ini dari semua kegiatan MPR yang dilakukan, maka Merchandising tampaknya kurang begitu menarik perhatian. Hal ini disebabkan oleh penjualan semua merchandise Film Habibie \& Ainun yang hanya dijual melalui sosial media dan website MD Entertainment, dan diharapkan setelah ini dilakukan penelitian lain mengenai pentingnya kegiatan Public Relations dalam mendukung pemasaran Film yang lebih spesifik dan mendalam, terutama dari para pekerja film Indonesia untuk semakin menggairahkan kembali perfilman nasional yang berkualitas.
\end{abstract}

Kata-kata Kunci: Film, public relations, pemasaran, strategi

\section{STRATEGY OF PUBLIC RELATIONS MARKETING OF MD ENTERTAINMENT IN MARKETING HABIBIE \& AINUN MOVIE}

\section{ABSTRACT}

The purpose of this research is to know the planning, implementation and evaluation of Public Relations Marketing strategy established by Public Relations (PR) of MD Entertainment on the marketing of film Habibie Ainun in 2012-2013. The method implemented in this research is descriptive method, aim to systematically delineate the fact or the characteristics of a particular population or a specific field in a factual and meticulous way. Results of the study indicate that PR of MD Entertainment has done some stages or the PR Technique on marketing the Habiebie and Ainun film, by doing the planning, implementation and evaluation of the programme from the year 2012-2013. Conclusion of this research is that PR of MD Entertainment constructing PR Marketing strategy planning for Habibie \& Ainun movie has been done really well and through a detailed process and preparation; stage of implementation of the strategy of the $M D$ Entertainment's marketing PR in marketing Habibie \& Ainun movie covers the: what, who and how to process to deliver messages to the community. They use varieties of tactics: in the form of Offline, Online and Ground Activity, highlights the Unique Selling point of the character, along with advertising, publicity, merchandising and assisted by the power of word of mouth. Evaluation of Strategies are also carried out by PR of MD Entertainment, starting with Media Monitoring, as well as finding what deficiency, the positives, and obstacles of activities coming out of the PR team.The suggestion coming out of this research are coming from all the activities of the Marketing PR has done. Merchandising is seem to be one of the weakest poin, due to the sale of all Movie merchandise for Habibie \& Ainun is only sold through social media and MD Entertainment website. It is expected that once this is done, other studies on the importance of Public Relations activities in specifically Movie marketing and insightful, especially from Indonesia to film workers increasingly exciting national cinema again.

Keywords: Film, public relations, marketing, strategy

Korespondensi:TrisnaAdiPermana,S.I.Kom,ProgramStudiHubunganMasyarakat,FakultasIlmuKomunikasi, Universitas Padjadjaran. Jalan Raya Bandung-Sumedang Km.21. Email: trisnaadipermana@gmail.com 


\section{PENDAHULUAN}

Public Relations bagi suatu lembaga produksi film merupakan suatu alat atau saluran publikasi dan komunikasi untuk memperlancar jalannya interaksi dan penyebaran informasi mengenai publikasi film yang diproduksi melalui kerjasama dengan pers media cetak maupun elektronik kepada masyarakat, sehingga masyarakat mengerti dan memahami apa yang sedang dikerjakan dan akan dihasilkan nantinya dalam rangka memberikan pilihan tontonan sangat menarik bagi masyarakat. Hal ini sejalan dengan tugas Public Relations yang salah satunya adalah menyebarkan informasi secara teratur mengenai produksi film yang direncanakan dan hasil yang telah dicapai. Sedangkan di sisi lain, diharapkan adanya "feedback" berupa partisipasi aktif masyarakat dalam merespons kehadiran film tersebut dengan menontonnya beramai-ramai ke bioskop.

Pengembangan sinergi dan fungsi marketing dan PR yang kemudian mencapai titik temu dan dikenal dengan istilah Marketing Public Relations cukup efektif dalam membangun pengenalan produk dan pengetahuan produk. Dalam beberapa hal, Marketing Public Relations dianggap lebih efektif untuk mencapai publisitas tinggi dalam proses publikasi, karena mengandung kekuatan membujuk dan sekaligus mendidik masyarakat atau publiknya. Manfaat dari MPR dalam perkembangan aktivitasnya dirasakan cukup efektif dan efisien, karena mampu menyebarkan pesan atau informasi yang disamping memiliki kemampuan untuk membujuk (persuasive approach) dan juga dapat mendidik (educated) publiknya atau masyarakat, lebih lagi dengan semakin ditambahnya kecanggihan teknologi informasi yang dipergunakan oleh media elektronik yang sudah serba canggih yang pada akhirnya menyebabkan MPR ini memiliki manfaat yang sangat berarti dalam mendukung bauran pemasaran (marketing mix) yang lebih khususnya lagi yaitu pada unsur promosinya.

Tolok ukur keberhasilan strategi Marketing Public Relations yang diterapkan untuk film adalah seberapa besar media massa tertarik untuk mempublikasikan film yang pada akhirnya turut berpengaruh kepada banyak jumlah penonton yang diraih. Keberhasilan film Habibie \& Ainun meraih jumlah penonton yang sangat fenomenal ditengah maraknya penayangan film lain baik lokal maupun asing, menunjukkan pentingnya kegiatan Public Relations yang diintegrasikan dengan pemasaran (marketing public relations) yang menjadi salah satu faktor yang mempengaruhi keberhasilan suatu film.

Untuk mendukung fokus penelitian ini maka dibuatlah pertanyaan penelitian yang terdiri dari perencanaan strategi Marketing Public Relations, implementasi strategi Marketing Public Relations MD Entertainment pada pemasaran film Habibie \& Ainun, dan evaluasi strategi Marketing Public Relations film Habibie \& Ainun tahun 2012-2013.

\section{METODE PENELITIAN}

Metode deskriptif adalah suatu metode dalam meneliti status sekelompok manusia, suatu objek, suatu set kondisi, suatu sistem pemikiran ataupun suatu kelas peristiwa pada masa sekarang. Tujuan dari penelitian deskriptif adalah untuk membuat deskripsi, gambargambar, atau lukisan secara sistematis, faktual dan akurat mengenai fakta-fakta, sifat-sifat serta hubungan antar fenomena yang diselidiki.

Menurut Whitney (1960), metode deskriptif adalah pencarian fakta dengan interpretasi yang tepat. Penelitian deskriptifmempelajarimasalahmasalah dalam masyarakat, serta tatacara yang berlaku dalam masyarakat serta situasi-situasi tertentu, termasuk tentang kegiatan-kegiatan, sikap, pandangan serta proses-proses yang sedang berlangsung dan pengaruh-pengaruh dari suatu fenomena (Nazir, 1988:63).

Penelitian ini dimaksudkan untuk menggambarkan Strategi Marketing Public Relations MD Entertainment pada pemasaran Film Habibie \& Ainun. Pada penelitian ini, peneliti menyusun data yang telah dikumpulkan yang berkaitan dengan masalah yang diteliti dan kemudian diklasifikasi lalu dianalisis secara deskriptif.

\section{HASIL DAN PEMBAHASAN}

Film yang diberi judul sesuai buku tulisan Habibie sendiri, "Habibie \& Ainun" ini, bertutur tentang kisah kasih keduanya dari remaja hingga masa senja, dari Indonesia sampai ke Jerman, hingga Ainun menutup usia di pelukan sang belahan jiwa. Kisah kasih keduanya ini tertuang dalam buku best seller karya Habibie sendiri berjudul, "Habibie \& Ainun", yang diangkat 
ke layar lebar oleh MD Pictures. Buku ini tidak hanya laris terjual di Indonesia tapi juga di berbagai negara lainnya. Bahkan buku ini sudah diterjemahkan ke berbagai bahasa selain Indonesia, seperti Inggris, Jepang, Jerman, dan lain sebagainya.

Diangkatnya biografi Habibie kedalam film, tidak lepas dari hubungan kedekatan tokoh Habibie dengan pihak MD Entertainment, khususnya dengan produser Manoj Punjabi. Seperti yang dinyatakan oleh Mita Nurani, PR Manager MD Entertainment:

“....Inilah yang menjadi cikal bakal kenapa kita membuat film Habibie dan Ainun karena sinetron cinta fitri itu semakin melambung ketika ibu Ainun Habibie almarhumah dan pak habibie dengan tidak malu malu menyatakan 'saya penonton penggemar cinta fitri sinetron'. Dari melihat istrinya suka nonton sampe kecanduan, jadi ketika mereka ke Jerman misalnya..kita kirim copynya...nah dari situ keluarlah di media media kalo pak habibie dan ibu ainun itu penonton fanatik itu makin melambung hingga sampe 7 season dibikin" (Wawancara dengan Mita Nurani, PR Manager MD Entertainment 5 Desember 2014).

Kedekatan tersebut ditegaskan juga oleh Manoj Punjabi, dalam salah satu siaran pers nya:

"Hubungan saya dengan Pak Habibie dan almarhumah Ibu Ainun memang sangat dekat, sudahseperti layaknya orang tua dan anak. Tapi ketika menggarap film tentang kisah kasih keduanya,saya harusprofessional. Bahkan tanggung jawabnya besar, dan menjadi lebih sulit karena tokoh yang difilmkan masih hidup. Terlebih Pak Habibie adalah orang yang kritis, dan memiliki daya ingat yang kuat, sampai ke detil-detilnya. Ini sebuah kehormatan sekaligus tantangan bagi saya". (Press Release)

Walaupun ada hubungan yang sangat dekat, tetapi pihak Produser dalam menggarap film tersebut, tetap mengutamakan profesionalisme untukmenghasilkan produkfilmyang berkualitas juga bisa laku di pasaran. Sebuah film dapat laris dan diterima oleh masyarakat ditentukan oleh beragam faktor. Tidak cukup dengan kekuatan film itu sendiri. Nama besar produser, sutradara dan acting dari para pemain di dalam film juga turut andil. Namun hal tersebut belumlah cukup. Karena banyak film yang dinilai bagus oleh pengamat film namun tidak sukses di pasaran. Pada Film Habibie \& Ainun sendiri, proses persiapan sudah dilakukan 2 tahun sebelum film ini ditayangkan. Dari mulai mengadaptasi biografi kedalam skenario film, memilih pemain dan sutradara, sampai survei lokasi shooting di Jerman, dipersiapkan secara matang oleh produser film agar dapat menghasilkan sebuah karya film yang berkualitas sekaligus dapat diterima oleh masyarakat luas.

Terkait dengan pertimbangan pemilihan genre film, dalam menghadapi persaingan di industri film Indonesia saat itu Mita Nurani PR Manager MD Entertainment menyatakan:

"sebetulnya kita sudah bikin film Ayat ayat Cinta, kan fenomenal juga kan.? Heboh banget. Prinsipnya kalo dari produser kita harus melawan trend..berani mendobrak.. jadi ketika orang lagi bikin film remaja Ada Apa Dengan Cinta..atau apa...Kita bikin Suster Ngesot...hebooh..trus orang ngikut bikin film horror...orang lagi setan setanan..kita bikin Ayat Ayat Cinta.. religius ..baru bikin Berkalung sorban lah... apalah...ngikut semua bikin... Abis itu kita bikin tentang Biografi yaitu Habibie Ainun...sekarang semua ngikut bikin Biografi...biografi Soekarno dll... kita sekarang lagi nyari lagi..kita lagi mau bikin film merry riana ini juga inspiring story tentang seorang motivator cewek yang meraih pendapatan 1 juta Dollar di usia 26 tahun." (Wawancara dengan Mita Nurani, PR Manager MD Entertainment 5 Desember 2014).

Ketika Manoj Punjabi selaku pimpinan MD Pictures mendapat kepercayaan

penuhuntuk mengangkat kisah ini ke layar lebar, ia tidak menyia-nyiakan kesempatan. Selama kurang lebih 2 tahun ia mempersiapkan segala sesuatunya dengan detil dan matang. Termasuk ketika Manoj harus turun langsung menentukan Reza Rahadian sebagai pemeran Habibie, Bunga Citra Lestari sebagai pemeran Ainun, serta memutuskan Faozan Rizal 
sebagai sutradara, serta Ginatri S. Noer dan Ifan Adriansyah Ismail sebagai penulis ceritanya

Hal ini sesuai dengan apa yang disampaikan oleh Ciria Staf PR MD Entertainment:

Proses perencanaan produksi berlangsung selama 2 tahun, cek lokasi dulu shooting, pertama kita buat synopsis global dulu... gambarannya akan seperti apa, cek lokasi dulu yang paling ribet itu di Jerman...kemudian harus nemuin rumah pak Habibie yang pertama kali di Bandung, baju tahun berapa...terus milih aktor juga ribet, aktor yang bisa niru pak Habibie itu tuh gak gampang, mempersonifikasi Habibie itu gak gampang...mempersonifikasi Habibie itu gak gampangada beberapa yang di casting soalnya Reza Rahadian itu option, tapi bukan last option..tapi dicasting hari terakhir bukan gak ada pilihan lain Cuma di-casting terakhir pilihannya waktu itu banyak, tapi Habibie kan termasuk orang yang kaya mimic yah...cara dia ngomong cara dia jalan selain itu bergerak gitu kalo yang lain pejabat kan kaku gitu sedangkan pak Habibie ekspresif, akhirnya setelah di casting lagi jatuhnya kepada Reza Rahadian.“.. Untuk pemilihan sutradara, Faozan itu dulu cameraman kita bisa liat lah pengambilan gambar yang bagus, banyak filmnya kan seperti Sang Pencerah... selain dari itu dia pasti dapat ilmu juga dari Hanung..dan pak Habibie juga setuju, dia juga ngarahin artis dengan baik...." (Wawancara denga Ciria Staf PR MD Entertainment)

Penulisan skenario film, mengikuti selera masyarakat Indonesia yang notabene menyukai hal-hal yang berbau romantisme, seperti yang disampaikan oleh Ciria, Staf PR MD Entertainment

"Film ini diangkat dari buku Habibie Ainun, yang merupakan dedikasinya pak Habibie untuk istrinya Ainun, jadi mostly bukunya tidak jauh dari film nya..tentang perjalanan percintaan mereka $80 \%$ deh..20\% nya perjalanannya politik, ada dia jadi presiden, wakil presiden... mungkin bapak Manoj itu orangnya yang menjual percintaan... tidak dipungkiri deh Indonesia itu suka hal yang berbau romantisme, jadi selain mengangkat figur ibu ainun (ibu kepala Negara) tapi ada sisi selling atau komersil juga, jadi mungkin itu yang melatar belakangi pak Manoj seperti itu, selain ada hubungan baik dengan Pak Habibie, bukunya best seller, kita juga mau mengangkat sisi romantik jadi lebih light gitu biografinya gak dokumenter membosankan...tapi ada drama percintaannya..sisi lain dari sosokpak Habibie dan Ibu Ainun yang biasanya pejabat itu kaku, ada birokrasi segala macem, jadi kita menuangkannya dalam bentuk yang bisa dinikmati lebih santai lebih ringan masuk kehati.." (Wawancara dengan Ciria Staf PR MD Entertainment)

Kesulitan dalam mengangkat kisah seorang tokoh ternama yang masih hidup kedalam film, diakui oleh Habibie sendiri, seperti yang dinyatakan dalam salah satu siaran pers:

"Ini tidak mudah lho, karena tokoh yang difilmkan serta beberapa pihak yang terkait di dalam cerita ini banyak yang masih hidup, bukan tokoh fiktif. Jadi orang bisa langsung membandingkan dan membuktikannya" (Pernyataan Habibie dalam Siaran pers yang dikeluarkan PR MD).

Adapun yang menjadi sasaran dari film Habibie \& Ainun, adalah seluruh masyarakat Indonesia, sesuai dengan segmen dari MD Entertainment seperti yang disampaikan oleh Mita Nurani:

"Target market itu kalo buat MD dari sinetron nya semua kalangan seluas luasnya, sebenernya kalo dilihat dari kelas kelasnya, pengkonsumsi sinetron kita di MNC itu kalo dipetakan itu di CD bawah, jadi kelas kelas yang bangsa..maaf..pembantu... suster jadi yang kaya gitu gitu...tapi waktu cinta fitri itu seorang Maksi Gunawan, seorang sosialita, seorang pengusaha laki laki lho.. kalo seorang ibu ibu sosialita sudah biasa, tetapi kalo bapak bapak penting, tokoh atau misalnya pengusaha kaya bias kalo sampe undangan sampe menunda acara karena menunggu cinta fitri selesai, itu membuat kita merasa berhasil mendobrak trend target yang kita targetin. Jadi ini adalah salah satu contoh kesuksesan kita dalam meluaskan target market, jadi kalo tadinya cuman C D E kebawah, ini sampe A+ kan kalo udah sampe presiden gitu..yang jelas kita sampe di Malaysia, Brunai, Singapur itu nonton sinetron kita semua itu bagus."

Film Habibie \& Ainun memiliki segmentasi yang menjadi sasaran konsumen perusahaan. Segmentasi ini sudah ditetapkan dari awal pembuatan film. MD Entertainment 
dalam menetapkan target sasaran juga melakukan segmentasi pasar. Segmentasi pasar ini merupakan suatu aktivitas membagi atau mengelompokkan pasar yang heterogen menjadi pasar yang homogen atau memiliki konsumen dalam hal minat, daya beli, geografi, perilaku pembelian maupun gaya hidup.

Sebelum masuk ke strategi komunikasi, hal yang harus diperhatikan terlebih dahulu dahulu produknya. Karena produk harus memiliki nilai jual ketika akan dipasarkan.Adapun definisi produk menurut Kotler adalah "A product is a thing that can be offered to a market to satisfy a want or need".

Produk adalah sesuatu yang bisa ditawarkan ke pasar untuk mendapatkan perhatian, pembelian, pemakaian, atau konsumsi yang dapat memenuhi keinginan atau kebutuhan. Produk yang ditawarkan adalah barang-barang yang meningkatkan value gaya hidup masa kini sehingga mudah menarik minat konsumen, termasuk soal film. Film adalah pertunjukan yang ditayangkan melalui media media layar lebar ataupun layar kaca. Film sebagai sebuah produk, agar berkualitas harus memperhatikan unsur-unsur pokok film sebagai berikut: (1) Penulis Skenario, (2) Sutradara, (3) Aktor/aktris, (4) Juru kamera, (5) Penyuntingan (editing), (6) Penata artistik, dan (7) Produser.

Perencanaan adalah proses menentukan dengan tepat apa yang di lakukan organisasi untuk mencapai tujuannya. Sedangkan pemasaran adalah seluruh sistem yang berhubungan dengan kegiatan untuk merencanakan dan menentukan harga hingga mempromosikan dan mendistribusikan barang dan jasa yang dapat memuaskan kebutuhan pembeli. Jadi rencana pemasaran/penjualan adalah proses menentukan dengan tepat untuk mempromosikan dan medistribusikan barang dan jasa sampai mencapai tujuannya yaitu memuaskan kebutuhan pembeli. Tujuan dibuat rencana tersebut sebelum memasarkan sebuah produk adalah agar apa yang dilakukan dalam memasarkan produk tesebut sesuai dengan tujuan yang ingin dicapai.

Terdapat 6 langkah perencanaan pemasaran yaitu analisis situsional, sasaran, strategi, taktik, anggaran, dan kontrol. Setelah target ditentukan yang berimplikasi kepada proses pembuatan produk, selanjutnya adalah penentuan tujuan dari perencanaan strategi MPR.

Menurut Mita Nurani, tujuan dibuat strategi
MPR ini adalah untuk membangun awareness konsumen terhadap film serta menarik minat konsumen untuk menonton film ini, dengan kata lain tujuan akhirnya adalah agar film ini laku di pasaran. Untuk itu perencanaan strategi Marketing PR digodog sebelum film ini tayang. Strategi yang akan digunakan adalah: Off Air, On Air dan Ground Activity.

"Jadi ketika proses shooting di luar..kita tim PR sudah menggodognya. Kalo off air sudah pasti..untuk mengepung sebuah promosi itu ada kegiatan off air... Ground Activity sama on air. Ini untuk apa ya biar awareness orang itu ditumbuhin.. (Wawancara dengan Mita Nurani, PR Manager MD Entertainment 5 Desember 2014)

Berdasarkan data penelitian, yang menjadi target sasaran dari kegiatan MPR Film Habibie dan Ainun adalah masyarakat umum seluas luasnya. Hal tersebut disampaikan oleh Ciria, Media Relations Officer MD Entertainment:

"..Targetnya semua orang Indonesia nonton, film nya laku.." (Wawancara dengan Ciria, Media Relations Officer MD Entertainment 14 Desember 2014).

Berdasarkan hasil wawancara tersebut, bisa diketahui bahwa tujuan dari Perencanaan MPR dalam memasarkan Film Habibie \& Ainun adalah menumbuhkan awareness masyarakat umum terhadap film, dan penjualan film, yang dapat dilihat dari jumlah penjualan tiket.

Seperti yang telah disampaikan sebelumnya bahwa Tolok ukur keberhasilan strategi MPR yang diterapkan untuk film adalah seberapa besar media massa tertarik untuk mempublikasikan film yang pada akhirnya turut berpengaruh kepada banyak jumlah penonton yang diraih. Untuk itu setelah melalui proses perencanaan yang dilakukan seiring dengan proses pra produksi film tersebut, PR MD Entertainment mulai melakukan promosi dengan berbagai taktik jauh sebelum film tersebut ditayangkan.

Berdasarkan data penelitian, pada pemasaran film Habibie dan Ainun, PR MD Entertainment mengembangkan taktik diantaranya pembuatan trailer, gimmick/ slogan, peluncuran album original soundtrack, pemasangan below the line,flyer, baligho dan billboard, radio interview, talkshow di televisi, roadshow dan jumpa fans, aktivasi sosial media 
dan website, quiz dan merchandise, press release, galapremiere, pendekatan kepada komunitas untuk direct selling/ partai besar, strategi fase I pra tayang, strategi fase II masa tayang, strategi fase III setelah masa tayang, serta evaluasi hasil strategi PR MD Entertainment pada Film Habibie \& Ainun.

Pertama, trailer. Trailer dibuat setelah melakukan pengeditan film, trailer adalah film singkat untuk promosi. Adegan-adegan yang diambil sebagai trailer adalah scene-scene menarik dan dianggap mampu mengundang rasa penasaran para penonton untuk menyaksikan film tersebut lebih lanjut. Agar trailer dapat ditonton oleh publik, maka trailer dibuat dua buah, yaitu yang berdurasi 30 detik untuk ditayangkan di media Televisi (RCTI sebagai media partner) dan website serta trailer yang berdurasi 2 menit untuk ditayangkan di seluruh jaringan 21. Trailer ini mulai dipublikasikan satu bulan sebelum film ditayangkan.

Kedua, gimmick/slogan. Tim PR MD membuat gimmick/slogan untuk Film Habibie dan Ainun: Be My Ainun. Hal ini bertujuan agar para calon penonton dengan mudah dapat mengingat film ini. Untuk mempublikasikan Gimmick ini, selain melalui berbagai kegiatan publikasi lainnya di media massa cetak, elektronik serta Online, juga melalui kegiatan Ground Activity. Yaitu dengan menyewa beberapa orang yang membawa rangkaian bunga serta membagikannya di mall setiap sabtu dan minggu, dengan bertanya: "Would you be my Ainun?" Hal ini bertujuan untuk menumbuhkan awareness khalayak terhadap film Habibie \& Ainun.

Ketiga, soundtract. Soundtrack juga dianggap sebagai media promosi yang baik. Original Soundtrack "Cinta Sejati" diproduksi oleh MD Music, ditulis oleh Melly Goeslow dan dinyanyikan oleh Bunga Citra Lestari yang sekaligus berperan sebagai Ibu Ainun, diluncurkan 4 bulan sebelum tayang. Selain itu dikeluarkan Video klip dari lagu tersebut yang ditayangkan di televisi-televisi nasional. Produksi dan Distribusi Soundtrack bekerjasama dengan Label Aquarius.

Keempat, baligho, billboard, flyer dan poster. "Kita juga mengeluarkan baligho, billboard, flyer, poster."Pemasangan Billboard di beberapa ruas jalan yang strategis di Kota Jakarta, ada yang diproduksi sendiri dan ada juga yang bekerjasama dengan sponsor (Sponsor yang memproduksi dan memasang). Poster dan Banner di semua jaringan 21.

Kelima, radio interview. Radio interview di beberapa radio jakarta dan kota kota besar yang menjadi sasaran roadshow dan jumpa fans. "Kampanye menggunakan artis melalui kegiatan on air dan off air, roadshow di beberapa kota, Media above the line, below the line" (Wawancara dengan Mita Nurani PR Manager MD Entertainment 5 Desember 2014)

Keenam, talkshow di televisi. Official Media Partner untuk Televisi adalah RCTIdan MNC Media. Namun untuk Talkshow sendiri, hampir di semua televisi swasta nasional dan lokal, seperti di acara: Just Alvin, Dahsyat, Bukan 4 Mata, Hitam Putih, Obsesi dan MNC News.

Ketujuh, roadshow dan jumpa fans. Roadshowdan jumpa fans dilakukan di kota Bandung, Palembang, Cirebon, Makasar, Surabaya dan Medan. Kegiatan roadshow dan jumpa fans merupakan suatu bentuk special events sebagai bagian dari strategi MPR Film Habibie \& Ainun bertujuan untuk mendekatkan sang bintang dengan publiknya. Untuk sebuah film hal ini sangat memberikan dampak positif karena kedekatan penonton dengan sang bintang akan sangat mendukung kesuksesan suatu film untuk mendapatkan tempat di hati penontonnya.

Kedelapan, aktivasi media sosial dan website. Aktivasi sosial media dan website yang dilakukan Yaitu melalui Official Account Twitter, Facebook, website MD Entertainment. Saat ini sosial media menjadi sebuah media informasi yang cukup penting di Indonesia. Informasi-informasi seputar film, mengadakan quiz berhadiah, melalui sosial media ini bertujuan untuk menyampaikan informasiinformasi terbaru seputar film agar lebih memancing minat konsumen agar menonton film ini.

Kesembilan, quiz dan merchandise. Tim PR MD Entertainment merancang beberapa quiz berhadiah dengan mesinergikan media media promosi seperti sosial media dan radio. Hal ini bertujuan untuk mengintegrasikan strategi komunikasi pemasaran agar memiliki dampak yang lebih kuat di kalangan konsumen film. Seperti yang disampaikan oleh Mita:

“.... banyak kita lakukan, sosial media seperti twitter, facebook dengan membuat games, kerjasama dengan radio, tabloid, mereka bikin pertanyaan tapi mereka link, sinergi..jadi 
ambil kuponnya dimana, jawabnya di radio, nontonnya dimana.." (Wawancara dengan Mita Nurani PR Manager MD Entertainment 5 Desember 2014)

Kesepuluh, press release. Press release - bisa disebut release/rilis adalah sebuah berita atau informasi yang disusun oleh sebuah organisasi yang menggambarkan kegiatannya. Jadi pada dasarnya press release merupakan berita tentang perusahaan (individu, kegiatan, pelayanan atau produk). Berita tersebut dikirimkan atau disiarkan ke media (pers), sehingga disebut juga siaran pers atau newsrelease.

Tim Humas MD Entertainment, mengeluarkan rilis secara berkala untuk menyampaikan informasi secara bertahap kepada kalangan media. Terdapat 6 release yang dibuat sebelum dan sesudah penayangan film, tujuannya adalah untuk menyampaikan sisi menarik dalam film ini, sehingga memancing rasa penasaran masyarakat untuk menonton.Press Release pertama : "K i s a h Kasih "Habibie \& Ainun" difilmkan MD Pictures" Press Release kedua:"Be my Ainun" (Ainun = Love)"Press Release ketiga:"BJ. HABIBIE MEMAKAI SEPATU BOLONG !" Press Release keempat:"Yang selalu dikatakan Ainun ke Habibie: THE BIG YOU AND THE SMALL I" Press Release kelima:“Janji Habibie Kepada Ainun: MEMBUATKAN PESAWAT TERAMAN DI DUNIA!"

Kesebelas, gala premiere.Gala Premiere merupakan suatu event khusus yang dirancang untuk memberikan informasi kepada khalayak akan kehadiran film Habibie \& Ainun. Tim MD membuat 2 Gala Premier, yang pertama yang dihadiri oleh pejabat tinggi Negara dan tamu undangan khusus seperti para duta besar, Gubernur DKI, para Menteri dll, serta Gala Premier untuk publik.

Hal ini bertujuan untuk memberikan dampak publisitas yang besar terhadap film ini, dan tentu saja melahirkan apa yang disebut dengan Word of Mouth. WOM memiliki kekuatan yang lebih besar dibandingkan dengan iklan maupun penjualan langsung, karena kekuatan WOM terletak pada kemampuannya dalam memberikan rekomendasi (referral). Word of mouth ini merupakan sebuah taktik MPR yang dampaknya membuat masyarakat semakin penasaran dan ingin menontonnya.

Keduabelas, pendekatan kepada komunitas untuk direct selling/partai besar. Selain menggunakan taktik sebelumnya, Tim PR juga melakukan pendekatan kepada komunitas, pemuka agama (pimpinan pesantren), Pabrik, Sekolah, dll yang sekiranya memiliki massa yang cukup banyak, untuk memfasilitasi mereka yang tidak memiliki kesempatan menonton film di bioskop-bioskop besar. Hal inilah yang menjadi pendukung, bagaimana film Habibie \& Ainun dapat memecahkan rekor penonton sampai menembus angka 4,7 juta.

Ketigabelas, strategi fase I pra tayang (dimulai 1 tahun sebelum tayang). Kegiatan yang dilakukan pada fase ini diantaranya Press Conference dan syukuran sebelum masuk masa Shooting (Shooting mulai 17 Juli - 19 September 2012), Media Release. meluncurkan album soundtrack Cinta Sejati, iklan trailer di TV RCTI, iklan trailer di Bioskop Jaringan 21, penayangan video klip "Cinta Sejati", publikasi di Twitter, Facebook dan Website MD Entertainment, Ground Activity "Be My Ainun" di Mall- Mall dan HI setiap Sabtu dan Minggu (H-1bulan), pemasangan poster film dan banner di seluruh jaringan bioskop 21, pemasangan Giant Billboard di beberapa jalan protokol di Jakarta, interview di Radio dan TV Swasta, menjual Merchandise berupa T-Shirt Couple "Be My Ainun" melalui twitter dan website.

Keempatbelas, strategi fase II masa tayang (Mulai 20 Desember 2012 - Maret 2013). Kegiatan yang dilakukan pada fase ini diantaranya Press Conference, Media Release, Gala Premiere, Talkshow TV, Interview di Radio, Roadshow, Jumpa Fans, Quiz di Radio, Twitter berhadiah gimmicks seperti tiket nonton gratis, merchandise, nonton bareng, Press Advertorial, dan pemasangan Giant Billboard di beberapa ruas jalan utama di Jakarta.

Kelimabelas, strategi fase III setelah masa tayang. Direct selling ke Pabrik, Oil Company, Pesantren dan Komunitas lainnya.

Terakhir, evaluasi hasil strategi MPR MD Entertainment pada Film Habibie \& Ainun. Proses evaluasi wajib dilakukan setiap selesai melaksanakan implementasi strategi agar perusahaan dapat mengetahui kekurangan dan kelebihan dari strategi yang telah dijalankan tersebut. PR MD Entertainment pun melakukan hal yang sama, berikut penjelasan dari Bu Mita:

"Ya jelas ada evaluasi, kalo dari pihak PR sih sudah dalam proses saat ini. Kita lihat bagaimana pemberitaan dari media, seberapa 
banyak, media mana yang meberitakan, kapan, kira-kira apa kekurangannya, apa kesalahannya, ada kendala apa tidak dalam pelaksanaannya, dan bagaimana hasilnya. Evaluasi itu waktunya introspeksi aja dari tim kami. Evaluasi itu dilakukan biasanya ya kaya rapat pleno aja, jadi seluruh tim humas melaporkan hasil kegiatan dari yang mereka kerjakan itu. Bagaimana prosesnya, bagaimana pelaksanaannya, bagaimana hasilnya, bagaimana respons masyarakat, bagaimana respons penonton, apa kendala yang dihadapi, apa kesulitannya, nanti kami ceritakan semua lah. Setelah semua melaporkan yaa dicari tau solusinya, apakah memang harus ada perbaikan dan sebagainya."

Menurut $\mathrm{Bu}$ Mita, pihaknya melakukan proses evaluasi dari apa yang sudah dilakukan selama pemasaran film Habibie \& Ainun. Prosesnya dimulai dari media monitoring hasil pemberitaan dari sejumlah media, baik cetak maupun elektronik. Lalu dalam proses evaluasi beliau mencari apa kekurangan, kelebihan, kendala yang dihadapi tim nya dalam melaksanakan tugas. Apabila evaluasi keseluruhan panitia itu dilakukan seperti rapat pleno, setiap divisi akan mempresentasikan bagaimana proses, bagaimana pelaksanaan, bagaimana hasil, bagaimana respons masyarakat, bagaimana respons penonton, apa kendala yang dihadapi, apa kesulitannya. Setelah semua disebutkan, akan dicari solusi terbaik untuk strategi Marketing PR kedepan.

\section{SIMPULAN}

Simpulan dari penelitian mengenai strategi marketing Public Relations MD Entertainment pada pemsaran film Habibie \& Ainun yang telah dilakukan melalui penelitian menggunakan metode deskriptif kualitatif dan dengan teknik pengumpulan data seperti wawancara, observasi, studi kepustakaan dan dokumentasi adalah perencanaan strategi marketing PR film Habibie \& Ainun telah dilakukan dengan baik dan melalui proses persiapkan yang sangat matang Diawali dengan dengan mengetahui apa kebutuhan dan keinginan konsumen sehingga produk mampu diserap oleh pasar. Pihak MD Entertainment sebelum memasarkan sebuah produk film, sangat mempertimbangkan kualitas produk film, sebelum melakukan strategi pemasaran agar dapat diterima oleh masyarakat.

Tahap implementasi strategi MPR MD Entertainment pada pemasaran Film Habibie \& Ainun meliputi apa, siapa dan bagaimana proses penyampaian pesan-pesan yang akan disampaikan kepada masyarakat. Penggunaan berbagai taktik MPR baik dalam bentuk Offline, Online dan Ground Activity yang menekankan pada Unique Selling point dari tokoh yang diangkat, disertai advertising/iklan, publisitas, merchandising dan dibantu oleh kekuatan word of mouth yang dilakukan oleh media dan masyarakat, tersebar ke semua lapisan masyarakat yang menjadi target sasarannya.

Proses Evaluasi Strategi juga dilakukan oleh PR MD Entertainment, diawali dengan melakukan Media Monitoring, serta mencari apa kekurangan, kelebihan, kendala yang dihadapi tim nya dalam melaksanakan tugas. Dari semua kegiatan MPR yang dilakukan, maka Merchandising tampaknya kurang begitu menarik perhatian. Hal ini disebabkan oleh penjualan semua merchandise Film Habibie \& Ainun yang hanya dijual melalui sosial media dan website MD Entertainment, dan tidak dijual secara langsung di toko-toko tertentu.

Diharapkan setelah ini dilakukan penelitian lain mengenai pentingnya kegiatan Public Relations dalam mendukung pemasaran Film yang lebih spesifik dan mendalam.

\section{DAFTAR PUSTAKA}

Nazir, M. (1988). Metode penelitian. Jakarta: Ghalia Indonesia

Whitney, F. (1960). The elements of research (Asian Edition). Osaka: Overseas Book Co. 